\title{
Reliability of organic compounds measurement in enviromental monitoring. The key role of analytical standard substance. A study case on alkylphenols.
}

\author{
Sophie Lardy-Fontan ${ }^{(1)}$, Claudine Chatellier ${ }^{(2)}$, François Lestremau ${ }^{(2)}$, Béatrice Lalere ${ }^{(1)}$, Marie-Pierre Strub ${ }^{(2)}$ \\ ${ }^{1}$ LNE, DMSI, Pôle Chimie Biologie 1 rue Gaston Boissier 75724 PARIS Cedex 15 \\ 2 INERIS, (French National Institute for Industrial Environment and Risks) Parc Technologique ALATA 3 Rue Jacques Taffanel 60550 \\ Verneuil-en-Halatte
}

\begin{abstract}
The overall management and decision making system driven by the Water Framework Directive (WFD) and other European water policies is strongly dependent on the quality of monitoring data. Performing fit for purpose measurements implies the demonstration of their metrological traceability, their procuration according to accurate and sensitive analytical methods and a realistic estimate of expanded uncertainty. This can only be achieved by the provision of reference measurement standard substances, whenever possible traceable to the SI, which serve as reference points for the implementation of a traceability infrastructure supporting a monitoring network in Europe. Routine laboratories operating in French water bodies monitoring program have repeatedly expressed to AQUAREF their difficulties regarding alkyphenols, one of the priority substances of the WFD. Accordingly, LNE and INERIS handled a study that aims at assessing the purity of nonylphenols commercially available analytical standard and discusses its impacts. The work highlights that: identity of the organic analytical standard substance reference materials should be clearly documented and demonstrated, purity assessment should be reported with a reliable uncertainty evaluation.
\end{abstract}

\section{Context}

The main aim of European water policy is to ensure that, throughout the EU, a sufficient quantity of good quality water is available for people's needs and for the environment [1]. Accordingly, an effective and coherent water policy, through numerous resolutions, has been settled up for more than 50 years. In 2000, the Water Framework Directive (WFD) marked a strong standpoint. It establishes the legal basis to protect and restore clean water across Europe and ensure its long-term, sustainable use [2]. It is designed to improve and integrate the management of EU water bodies by enhancing the status and preventing further deterioration of aquatic ecosystems and associated wetlands, promoting a sustainable use of water, reducing pollution of water bodies, especially by (dangerous) priority substances and ensuring a progressive reduction of groundwater pollution. Its operational implementation is ensured thanks to a set of directives addressing specific points.

The directive 2009/90/EC of 31 July 2009, so-called $\mathrm{QA} / \mathrm{QC}$ directive, lays down the technical specifications for chemical analysis and monitoring of water status [3]. It specifies that "The quality and comparability of analytical results generated by laboratories appointed by competent authorities of the Member States to perform water chemical monitoring pursuant to Article 8 of Directive 2000/60/EC should be ensured" and in its article 3 that "all methods of analysis, including laboratory, field and on-line methods, used for the purposes of chemical monitoring programmes carried out under Directive 2000/60/EC are validated and documented in accordance with EN ISO/IEC 17025 standard or other equivalent standards accepted at international level."

The EN ISO/IEC-17025 standard specifies the general requirements for the competence to carry out tests and/or calibrations and emphasizes the importance of traceability of measurement [4].

Accordingly, laboratories are required to demonstrate the metrological traceability of their measurement results in order to operate in conformity with the requirements of ISO 17025.

The concept of traceability of measurement can be strongly linked to the concept of quality of measurement. The key elements that sustain high quality measurements are detailed in Figure 1. Fig1a) presents a metrological vision i.e. for a given measurement to be considered of high quality, it has to be demonstrated comparability, through traceability to S.I. units, reliability, accuracy and a prescribed level of uncertainty. That is not sufficient. In fact, that does not mean that it is fit for purpose as underlined by Fig $1 b$.

\footnotetext{
${ }^{a}$ Corresponding author: sophie.lardy-fontan@lne.fr
} 

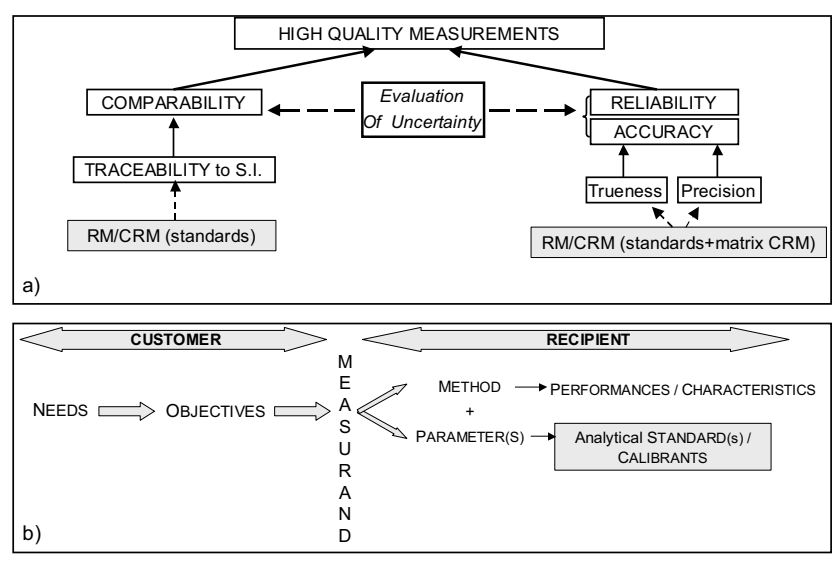

Figure 1: High quality measurements requirements

a) the metrological requirements

To sustain the need of more reliable measurements, this study handled by two laboratories: LNE and INERIS focuses on one of the more critical parameters included in the WFD: Nonylphenols. It aims at studying the purity of commercially available analytical standard and discusses its impacts.

\section{What are nonylphenols?}

Nonylphenols (NP) are mass-produced chemical compounds. They have been used in various domestic detergents, paints, herbicides, pulp and paper production, textile manufacturing, pesticide formulations and industrial cleaning agents and wherever their interfacial effects of detergency, (de)foaming, (de)emulsification, dispersion or solubilization can enhance product or process performance The industrial NP process results in a highly complex mixture of isomers: isomers of substitution (ortho, meta, para) and isomers of branched alkyl chains (Figure 2). No less than 550 isomers are theoretically possible. Linear isomer of nonylphenol is not present in the technical mixture. The batch to batch isomeric pattern of technical mixtures can be highly variable as no reference exists. A growing interest has taken place on their occurrence and fate in the environment - especially because they exhibit potencies of endocrine disruption. Only 50 to 80 isomers of nonylphenols have been determined in environmental studies. For some more information, the authors recommend the following review $[5 ; 6]$.

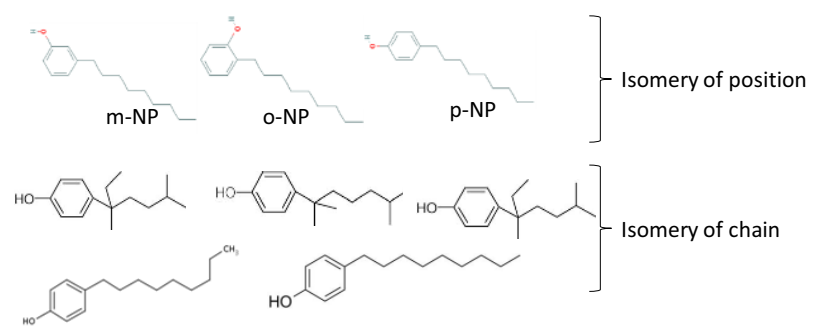

Figure 2: Illustration of the isomers of nonylphenols On the left part: illustration of the 3 isomers of position

On the right part: illustration of some possible isomers of chain (linear and ramified).
The complexity of nonylphenols is also noticeable when looking at the Chemical Abstract Service (CAS) register. In fact, as demonstrated in Table 1 which sums up the principal CAS: 84852-1563, 25154-52-3,104-40-5 and 11066-49-2 that encompasses nonylphenols, the ambiguity is evident.

Table 1: CAS register of nonylphenols

\begin{tabular}{|l|l|l|}
\hline \hline CAS Number & $\begin{array}{l}\text { Definition of the chemical } \\
\text { product (To date) }\end{array}$ & $\begin{array}{c}\text { 作 } \\
\text { cheminition of the } \\
\text { (Anterior) }\end{array}$ \\
\hline $84852-15-3$ & $\begin{array}{l}\text { Mixture of isomers of } \\
\text { position of nonylphenols } \\
\text { with linear chain }\end{array}$ & $\begin{array}{l}\text { Mixture of isomers of } \\
\text { positions and chains of } \\
\text { nonylphenols }\end{array}$ \\
\hline $25154-52-3$ & $\begin{array}{l}\text { Mixture of isomers of chains } \\
\text { of p- nonylphenol s }\end{array}$ & NR \\
\hline $104-40-5$ & $\begin{array}{l}\text { Linear isomer of p- } \\
\text { nonylphenol }\end{array}$ & NR \\
\hline \hline & $\begin{array}{l}\text { Mixture of isomers of } \\
\text { position of nonylphenols } \\
\text { with one ramification of } \\
\text { chain (not specified) eg } \\
\text { isononylphenol }\end{array}$ & NR \\
\hline \hline
\end{tabular}

\section{Theory of purity assessment in chemistry}

To date, there is no definition of "purity" in the International Vocabulary of Metrology.

The content of pure material is usually estimate by an indirect determination approach (so called mass balanced approach). The quantitative determination of all significant impurities such as water, residual solvents, reaction by-products, isomeric compounds, or matrix compounds stemming from the isolation from natural products or other mixed sources, is summed and subtracted from $100 \%$. Such analyses are not trivial and needs expensive instrumentation. An alternative is the direct determination where the absolute determination of the analyte, instead of the impurities, is performed, for instance, by quantitative NMR or titration.

\section{Study design}

In the present work, only commercial products which are labeled by the provider as "technical nonylphenol" and / or have the CAS 84852-15-3 were selected.

A set of eight products have been identified for this study (table 2):

- six products with the 84852-15-3 CAS number,

- one "technical nonylphenol" produced with the CAS number 25154-52-3,

- one "technical nonylphenol" produced with the CAS number 11066-49-2.

A description of each reference is provided in Table 2.

The characterization of the technical mixtures of 4nonylphenol was carried out according to the ISO 24293 standard that specifies a method for the determination of selected individual isomers of nonylphenol based on gas phase chromatography coupled to flame ionization detection (GC/FID) [7].

Purity assessment was achieved following the mass balanced approach. Impurities such as water, residual solvents, and inorganic compounds were not considered 
as the work aimed to focus on isomeric impurities and impurities derived from the synthesis.

\section{Purity assessments of the different analytical standards}

Figure 3 presents the comparison of purity estimate as conducted in the present work (green) and the purity estimate - when available- of the provider certificate (blue).

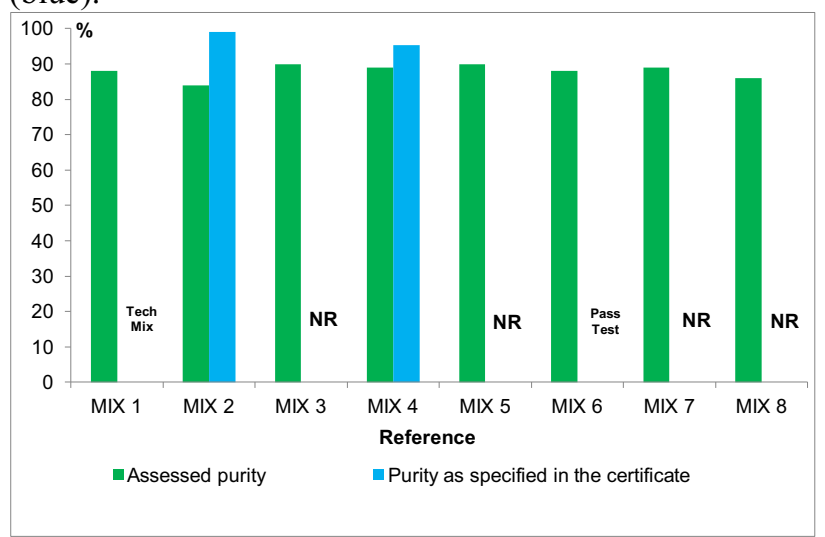

Figure 3a: Comparison of the purity of the 8 references between the present work estimate and the certificate

The following points can be highlighted:

-Among the 8 selected references, only 2 provided information about quantitative purity and 2 about qualitative ones/the composition of the mixture;

- Purity estimates in the present work are systematically determined below the purity of the certificate;

- For highly complex mixtures of isomers such as nonylphenols; HPLC-UV - the most conventional analytical method employed for purity assessment in organic chemistry, the peaks resolutions are not sufficiently achieved (figures 4 and 5).

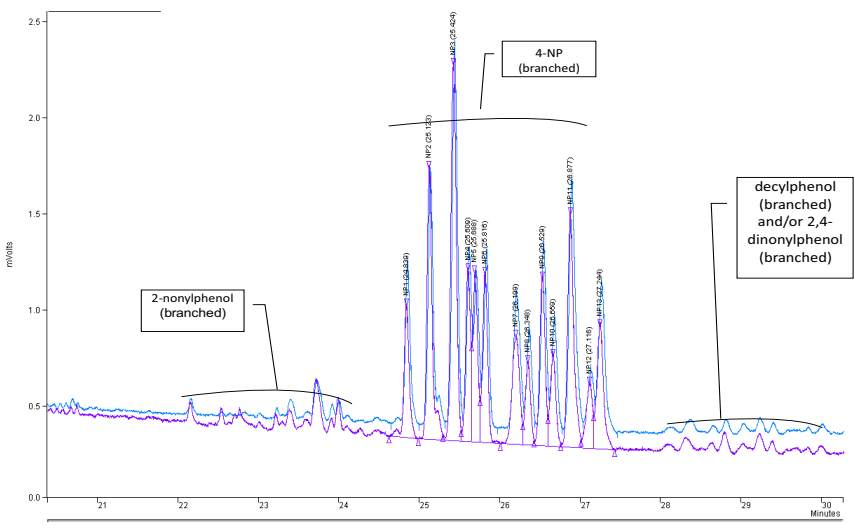

Figure 3b: Analysis of Mix 1 (blue) and Mix 9 (purple) by GC/FID

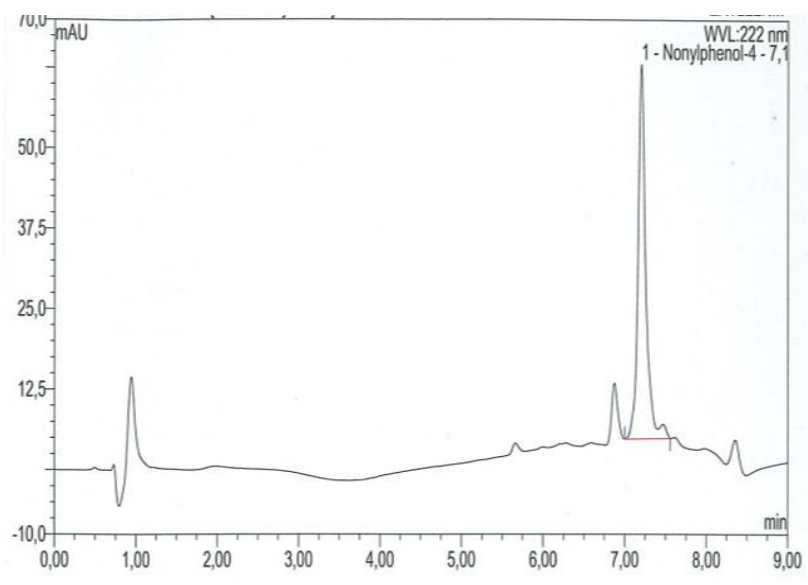

Figure 4: Analysis of Mix 1 by HPLC/UV

Table 2: Commercial products available labeled as technical mixture of nonylphenols

\begin{tabular}{|c|c|c|c|c|c|c|c|c|}
\hline Denomination & $\begin{array}{c}\text { Nonylphenol- } \\
4\end{array}$ & $\begin{array}{l}\text { Nonylphenol } \\
\text { PESTANAL® } \\
\text { analytical } \\
\text { standard }\end{array}$ & $\begin{array}{l}\text { Nonylphenol } \\
\text { technical } \\
\text { grade, } \\
\text { mixture of } \\
\text { ring and } \\
\text { chain isomers }\end{array}$ & $\begin{array}{l}\text { Nonylphenol } \\
\text { mixture of } \\
\text { ring and } \\
\text { chain isomers } \\
\text { Tech. Grade }\end{array}$ & $\begin{array}{c}4- \\
\text { nonylphenol } \\
\text { (mixture of } \\
\text { branched } \\
\text { chain } \\
\text { isomers) }\end{array}$ & Nonylphenol & $\begin{array}{l}\text { Nonylphenol } \\
\text { technical } \\
\text { grade, } \\
\text { mixture of } \\
\text { ring and } \\
\text { chain isomers }\end{array}$ & $\begin{array}{c}\text { Nonylphenol } \\
\text { Technical }\end{array}$ \\
\hline $\begin{array}{c}\text { Chemical } \\
\text { Abstract } \\
\text { Service } \\
\text { Number }\end{array}$ & [84852-15-3] & [84852-15-3] & [84852-15-3] & [84852-15-3] & [84852-15-3] & [84852-15-3] & [11066-49-2] & [25154-52-3] \\
\hline Manufacturer & $\mathrm{A} 2 \mathrm{~S}$ & Sigma-Aldrich & Aldrich & $\begin{array}{c}\text { Pfaltz \& } \\
\text { Bauer }\end{array}$ & TCI & Accustandard & Aldrich & $\begin{array}{c}\text { Dr } \\
\text { Ehrenstorfer }\end{array}$ \\
\hline Supplier & CIL-Cluzeau & Sigma-Aldrich & $\begin{array}{l}\text { Sigma- } \\
\text { Aldrich }\end{array}$ & Interchim & Interchim & Interchim & $\begin{array}{l}\text { Sigma- } \\
\text { Aldrich }\end{array}$ & CIL-Cluzeau \\
\hline Reference & N038P100 & 46018 & 290858 & N14080 & N0300 & D-7485-01 & 290858 & 15629000 \\
\hline Purchase Date & March 2013 & February 2014 & February 2014 & February 2014 & $\begin{array}{c}\text { February } \\
2014\end{array}$ & February 2014 & February 2002 & March 2013 \\
\hline
\end{tabular}




\begin{tabular}{|c|c|c|c|c|c|c|c|c|}
\hline $\begin{array}{c}\text { Purity as } \\
\text { specified in the } \\
\text { certificate }\end{array}$ & $99.0 \%$ & $95.4 \%$ & NR & «Pass Test » & NR & «Tech. mix » & NR & NR \\
\hline $\begin{array}{c}\text { Method of } \\
\text { purity } \\
\text { assessment }\end{array}$ & HPLC/UV & $\begin{array}{c}\text { GC/MS } \\
\text { Karl-Fisher }\end{array}$ & NR & GC & NR & GC/FID & NR & NR \\
\hline $\begin{array}{c}\text { Codification in } \\
\text { this work }\end{array}$ & Mix 1 & Mix 2 & Mix 3 & Mix 4 & Mix 5 & Mix 6 & Mix 8 & Mix 9 \\
\hline
\end{tabular}

HPLC/UV: Liquid phase chromatography coupled to UV detector; GC/MS: Gas phase chromatography coupled to mass spectrometry; GC/FID: Gas phase chromatography coupled to Flame Ionization detector, NR: not specified

\section{Conclusions/ Keys messages}

In conclusion, analytical standards used by laboratories for routine monitoring of 4-nonylphenol (4-nonylphenol or branched) are poorly characterized by the manufacturers. In many cases, mixtures are sold under the name "nonylphenol" which means that they are composed mostly of 4-nonylphenol but also of 2nonylphenol (between 5 and 10\%). This implies that the degree of purity of 4-nonylphenol is either not known by the manufacturer, or is incorrect in the case where it is provided. Finally, it should also be mentioned that the certificates accompanying such standards are not very explicit both in the identification of the substance or its purity.

The following recommendations are suggested:

- The selection of an appropriate analytical standard material is a highly critical step as it supports the adequation between the measurand and the objectives of the study;

- The purity of a material and its uncertainty must be known based on sound analytical investigations;

- The purity of a material and its uncertainty must be taken into account in the expression of the final measurement's result as it can represent a significant contribution in inaccuracy of environmental measurements;

- Purity assessment of standard material must be more rigorously addressed by manufacturers and available for customers

- Purity assessment of standard material must be addressed by relevant analytical tools eg GC/ FID for alkylphenols;

- Certificate of analysis must be improved to sustain the need of laboratories to implement ISO 17025 requirements.

\section{References}

[1] Communication from the commission to the European parliament, the council, the european economic and social committee and the committee of the regions. A Blueprint to Safeguard Europe's Water Resources, COM (2012) 673 final, 24 pages.

[2] Directive 2000/60/EC of the European Parliament and of the Council of 23 October 2000 establishing a framework for Community action in the field of water policy.

[3] QA/QC Directive (2009/90/EC), "COMMISSION DIRECTIVE 2009/90/EC of 31 July 2009 laying down, pursuant to Directive 2000/60/EC of the European Parliament and of the Council, technical specifications for chemical analysis and monitoring of water status".
[4] ISO/IEC 17025 International Standards Organisation, General requirements for the competence of testing and calibration laboratories (2005).

[5] S. Rabouan, A. Dupuis, A. Cariot, M. Albouy-Llaty, B. Legube, V. Migeot. TrAC 37, 112-123 (2012).

[6] A. Soares, B. Guieysse, B. Jefferson, E. Cartmell, J.N Lester. Environ. Int. 34(7) 1033-1049 (2008).

[7] ISO 24293 Water quality - Determination of individual isomers of nonylphenol - Method using solid phase extraction (SPE) and gas chromatography/mass spectrometry (GC/MS) 